\title{
FUNCTIONAL ANALYSIS OF RESTORING THE PILLARS OF DISTAL HUMERUS FRACTURE WITH 90-90 PLATING- A CASE SERIES
}

\author{
Pugalenthi Vijayarahavan', Neelaiappan Thanappan², Jawaharlal Nehru Maheswaram³, Jeyaraman Sivaprashanth4
}

${ }^{1}$ Chief Professor and HOD, Department of Orthopaedics and Traumatology, Madurai Medical College, Madurai, Tamilnadu.

${ }^{2}$ Chief Professor (Associate), Department of Orthopaedics and Traumatology, Madurai Medical College, Madurai, Tamilnadu. ${ }^{3}$ Assistant Professor, Department of Orthopaedics and Traumatology, Madurai Medical College, Madurai, Tamilnadu. ${ }^{4}$ Postgraduate Student, Department of Orthopaedics and Traumatology, Madurai Medical College, Madurai, Tamilnadu.

\section{ABSTRACT}

\section{BACKGROUND}

Distal humerus fracture is one of the commonest fractures of young adult and elderly individuals. The treatment of these fractures continues to present challenges despite advances in internal fixation.

\section{MATERIALS AND METHODS}

A total of 25 fresh patients of comminuted fracture of humerus from Jan 2012 to Jan 2017 were included in the study and were treated with orthogonal plating. These patients were followed at 3, 6, 12, 24 weeks and at 1 year of follow-up and assessed in terms of time for union, range of motion, MAYO score, DASH score and complication rate.

\section{RESULTS}

At final follow-up, Mayo score was $96.12 \pm 04.96$ from 4.80 \pm 01.06 and DASH SCORE was 30.42 \pm 2.04 which dropped from $150 \pm 05.24$. Range of motion improved from 23.38 to 114.1 with $100 \%$ union rate and complications less than $17 \%$.

\section{CONCLUSION}

90 - 90 plating for distal humerus fractures is excellent method of fixation and results are similar to those treated with parallel plating.

\section{KEYWORDS}

Orthogonal, Unstable, Osteotomy, Mayo Elbow Performance Score.

HOW TO CITE THIS ARTICLE: Vijayarahavan P, Thanappan N, Maheswaram JN, et al. Functional analysis of restoring the pillars of distal humerus fracture with 90-90 plating- a case series. J. Evolution Med. Dent. Sci. 2018;7(16):2044-2047, DOI: $10.14260 /$ jemds/2018/459

\section{BACKGROUND}

Fractures of the distal humerus account for approximately $2 \%-4 \%$ of all fractures and about $25 \%$ of all elbow fractures.[1] Attention should be given to the mechanism of injury, the condition of the soft tissues, the bone quality and lastly the age and physical demands of the patient. Even with development of newer fixation techniques, the treatment of distal humerus fractures remains a challenge to every orthopaedic surgeon. Due to complex anatomy of elbow along with metaphyseal and articular comminution, good results are difficult to achieve.[2] To obtain good results, anatomical reduction with rigid fixation and early range of mobilisation is required.[3] Due to the characteristic intra-articular involvement and poor control of fracture fragments with closed treatment, these fractures are treated operatively to achieve anatomic reduction and stable fixation of the fractured fragments. ${ }^{[4]}$ Double plate fixation is considered the correct treatment for a comminuted intra-articular fracture of the distal humerus. [5-7]

'Financial or Other Competing Interest': None.

Submission 28-02-2018, Peer Review 02-04-2018,

Acceptance 09-04-2018, Published 16-04-2018.

Corresponding Author:

Jeyaraman Sivaprashanth,

10/2, Indranagar $2^{\text {nd }}$ Street,

Kalavithyanathapuram,

Madurai-18

Tamilnadu.

E-mail: jsivaprashanth@gmail.com

DOI: $10.14260 /$ jemds $/ 2018 / 459$
The purpose of this study was to determine the outcome of treating these fractures with a principle-based technique that maximum fixation in the articular fragments and stability at the supracondylar level. The technique was specifically designed to satisfy two principles: 1 . Fixation in the distal fragments should be maximised; 2 . Screw fixation- the proximal segment should contribute to stability at supracondylar level. The early stability with this technique permits intensive rehabilitation to restore elbow motion. Due to this unique anatomy of the distal humerus, various plates have been developed to try and provide adequate stability to the articular, metaphyseal and diaphyseal regions of the distal humerus. These plates include Y-shaped plates, recon plates contoured to the anatomy and recently pre-contoured plates with or without locking screw capabilities. The anatomical location to place the plates on the distal humerus has recently been debated throughout the literature with the majority of authors currently recommending at least two plates be utilised to provide adequate stability and allow for adequate restoration of anatomy. Orthogonal plating, otherwise known as 90-90 plating or perpendicular plating, involves placing one plate on the medial column of the distal humerus and the other plate along the posterolateral column. The concept of parallel plating involves placing one plate along the medial column of the distal humerus and the other plate along the lateral column. We did a prospective study of orthogonal plate fixation of fractures of distal humerus in adults. 


\section{MATERIALS AND METHODS Specimens}

All fresh cases of distal humerus fracture reporting to us from January 2015 to January 2017 were included in this study. Informed written consent was taken from all. This prospective study included 25 patients. Patients were excluded if they had pre-existing deformity, disability, infection, previous surgical intervention in the involved elbow, unfit for surgery or failure to give consent. The patients were taken up for surgery after preoperative investigations and fitness for anaesthesia was assured. Digital pneumatic tourniquet was used in all. Intravenous antibiotics were given six hours before surgery and for next two days in postoperative period and further five days oral antibiotics were given.

\section{Preparations and Approaches}

The patients were taken up for surgery after regional/general anaesthesia in lateral decubitus position with arm supported and forearm hanging. The limb was painted and draped before proceeding for the exposure of the elbow. Elbow was exposed through standard midline posterior approach with incision beginning $5 \mathrm{~cm}$ distal to the tip of the olecranon and extending proximally in the arm up to $8 \mathrm{~cm}$ above the tip of the olecranon. Ulnar nerve was exposed and secured. A ' $V$ ' or transverse shaped olecranon osteotomy was done to get better exposure of the articular surface in 20 cases, Campbell triceps splitting 5 cases. Bone fragments were reduced and held with ' $\mathrm{K}$ ' wires. Fracture was then fixed with intercondylar screw and $3.5 \mathrm{~mm}$ reconstruction plates which were placed 90 to each other on medial and lateral [posterolateral] columns. The stability of the internal fixation was tested by moving the elbow through full range of motion. The Olecranon osteotomy was then reduced under direct vision and fixed by figure-of-eight tension band wiring or 6.5 cancellous screw. After fixation of the osteotomy, the elbow was again put through the range of motion to test the stability of fixation. The tourniquet was released, and haemostasis achieved over a negative suction drain and the wound was closed in layers. Pressure bandage was applied.

\section{Postoperative Follow-Up}

In the postoperative period, the limb was kept elevated. Active movement of fingers and elbow joints were encouraged on the heels of pain from second postoperative day. Suction drain was removed after $24 \mathrm{~h}$. Wound was inspected after 3 - 4 days postoperatively. Antibiotics and analgesics were given to the patient till the time of suture removal. Suture/ staples were removed on the 12th postoperative day. Postoperative radiographs were obtained as soon as patient was comfortable. Elbow was mobilised through full range of movement at least twice daily and patient was discharged on 12th postoperative day with instruction to carry out physiotherapy in the form of active flexion-extension and pronation-supination exercises without loading. Patient was assessed after $6 \mathrm{wks}, 12 \mathrm{wks}$ and $24 \mathrm{wks}$ of surgery. At every follow-up a detailed clinical examination was done, and patient was assessed subjectively for the pain, swelling, range of joint motion and radiological union. The functional assessment of the patient was done according to Mayo elbow performance score and Quick DASH score.

\begin{tabular}{|c|c|c|c|}
\hline $\begin{array}{c}\text { Time } \\
\text { Interval }\end{array}$ & $\begin{array}{c}\text { Range of } \\
\text { Motion }\end{array}$ & Mayo Score & DASH Score \\
\cline { 2 - 4 } & Mean & Mean & Mean \\
\hline $\begin{array}{c}\text { 1st } \\
\text { postoperative } \\
\text { week }\end{array}$ & $(10-50) 23.38$ & $(02-08) 04.80$ & $(120-167) 150$ \\
\hline $\begin{array}{c}3 \text { weeks } \\
\text { follow-up }\end{array}$ & $(10-95) 71.67$ & $(60-75) 66.43$ & $(70-80) 73.57$ \\
\hline $\begin{array}{c}6 \text { weeks } \\
\text { follow-up }\end{array}$ & $(80-115) 98.33$ & $(70-90) 82.62$ & $(31-46) 38.14$ \\
\hline $\begin{array}{c}3 \text { months } \\
\text { follow-up }\end{array}$ & $\begin{array}{c}(95-120) \\
111.46\end{array}$ & $(85-100) 90.79$ & $(30-37) 32.84$ \\
\hline $\begin{array}{c}6 \text { months } \\
\text { follow-up }\end{array}$ & $(85-120) 115.0$ & $(85-100) 93.42$ & $(30-37) 31.63$ \\
\hline $\begin{array}{c}\text { 1 year follow- } \\
\text { up }\end{array}$ & $(85-120) 114.1$ & $(85-100) 96.12$ & $(30-37) 30.42$ \\
\hline $\begin{array}{c}\text { [Table/Fig-1]: Showing Comparative Data of different } \\
\text { Clinical and Functional Parameters }\end{array}$ \\
\hline
\end{tabular}

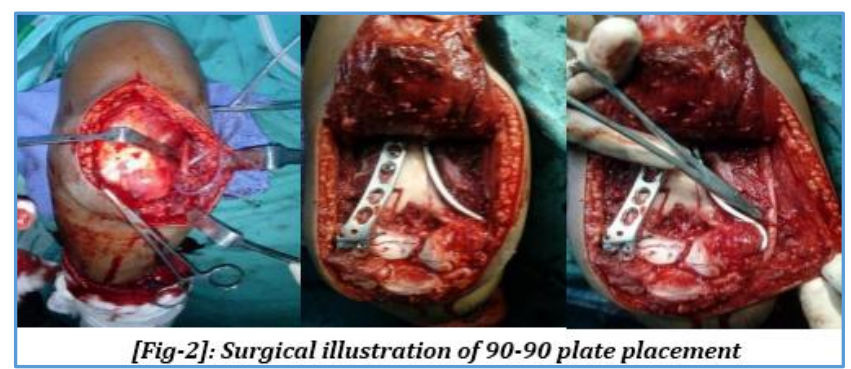

\section{Case Illustration}
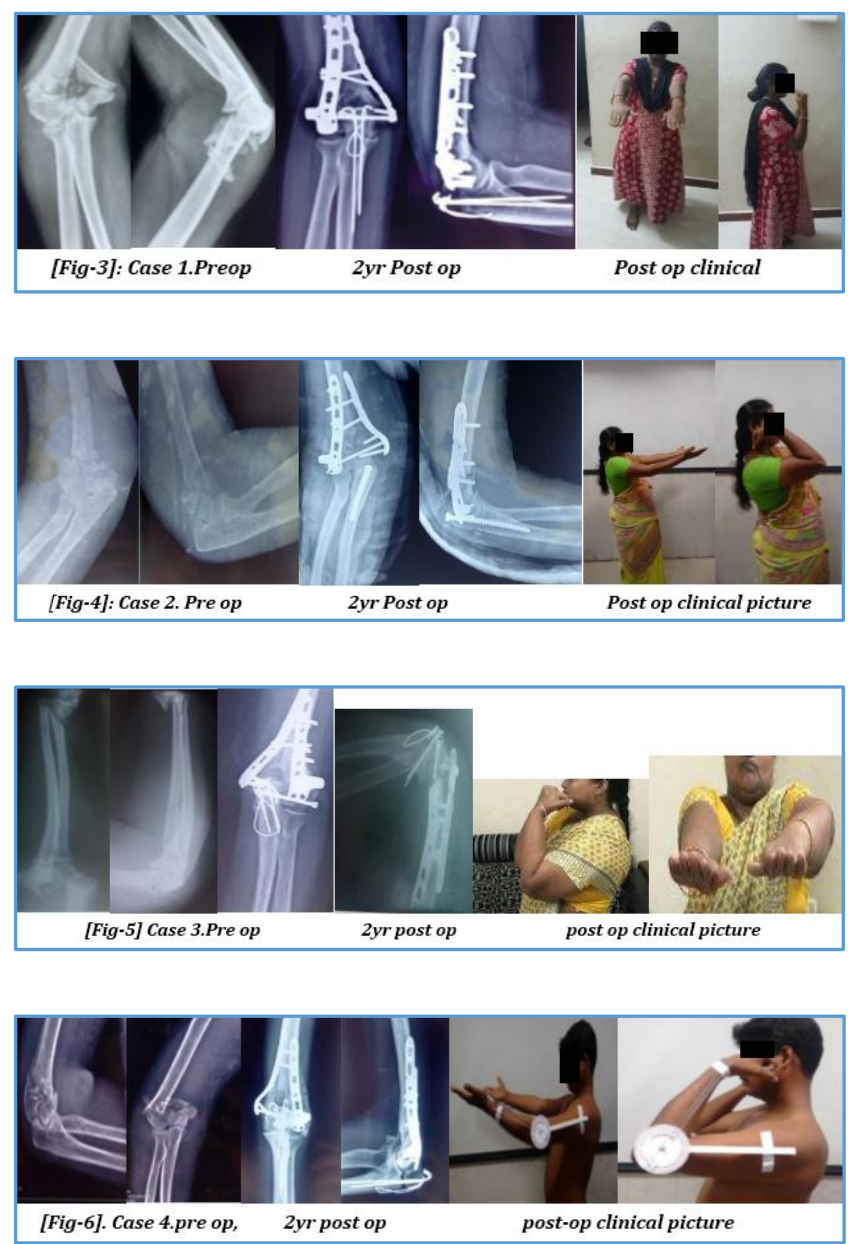

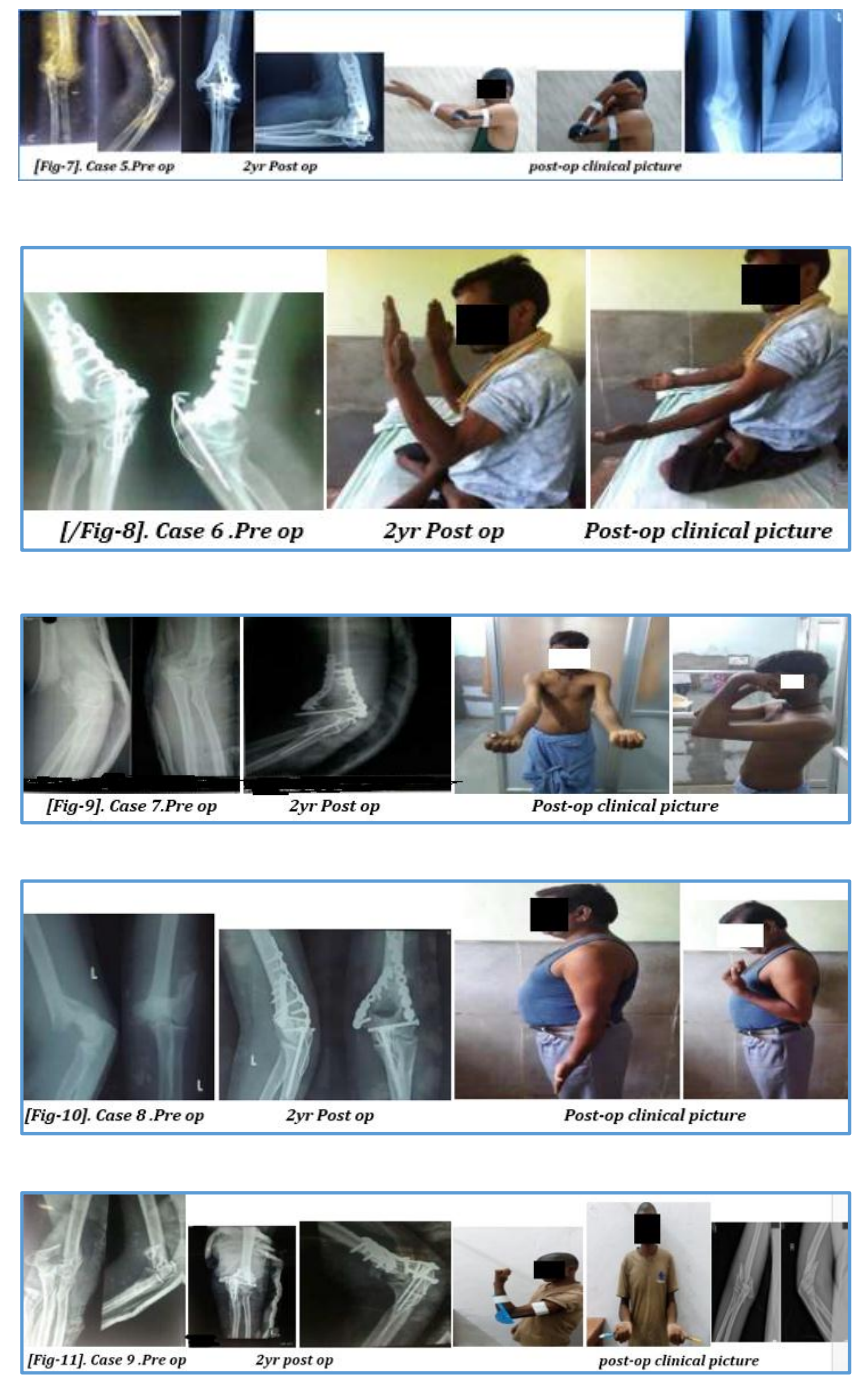

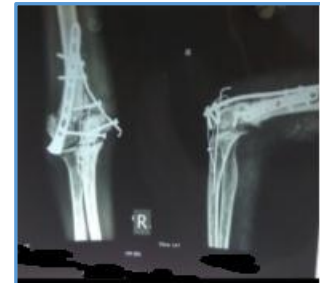

[Fig-12]. Case 10.Pre op

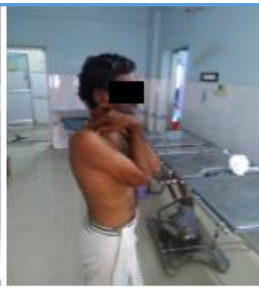

2yr Post op

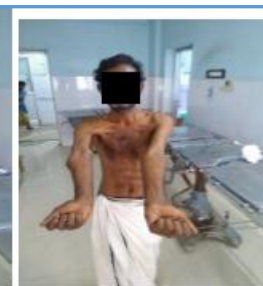

Post-op clinical picture

\section{DISCUSSION}

The concept of 90-90 plating evolved as 180 plating did not provide adequate fixation and enough stability in high percentage coronal fracture cases.[8-10] All our cases achieved union within four months. Non-union or delayed union is not a problem in these fractures as shown by most of the studies [Table/Fig-8]. Mean range of motion $(116.1 \pm 7.92)$ at final follow-up in our series is greater than that reported by some authors.[11] But there are also reports, which claim full or nearly full range of movement postoperatively.[8-10] Mayo score in different studies has been reported from 72.3 to 96.32. Mayo scores above 90 have been shown to be achieved in only one worker. ${ }^{[8]}$ Higher scores in present study could be attributed partly to the younger age profile of our patients. This indicates that maximum benefit can be achieved with aggressive physiotherapy in first three months of surgery [Table/Fig-1]. This can only be achieved if anatomical rigid fixation is done. Complication rates vary from $6 \%$ to $44.4 \%$ in different studies. In present study one deep infection, three superficial suture line infections occurred which resolved with a short course of antibiotics [Table/Fig-8]. Comparison of perpendicular and parallel plating in a single study was done by only one researcher. Statistically, no significant difference was found between the outcomes of parallel plating and perpendicular (Orthogonal) plating. On the basis of results reported in literature, comparison of functional outcome of present study and orthogonal plating studies in terms of union rate and functional outcome, range of motion, Mayo score, DASH score and complication was done [Table/Fig-9]. A comparison of results of present study and studies reporting results after orthogonal plating was done, which shows no significant difference between two groups with respect to union time, Mayo score and DASH score [Table/Fig-9]. There is no difference between the plates and complication rates could be observed based on this parameter. However, with respect to range of motion, our results are relatively better. The Mayo scores also indicated a better outcome in present study. In general, our results are similar to those reported by others who did not find a significant difference between two techniques in terms of functional outcome.[12,11] We achieved excellent union rate, range of motion and functional scores. The results of orthogonal plating are encouraging, and we endorse this method based on the findings of present study.

\section{CONCLUSION}

All cases united within six months with good function, hence we can conclude that orthogonal plating for distal humerus fractures is an excellent method of fixation and results are similar to those treated with parallel plating.

\section{REFERENCES}

[1] Korner J, Lill H, Müller LP, et al. The LCP-concept in the operative treatment of distal humerus fracturesbiological, biomechanical and surgical aspects. Injury 2003;34(Suppl 2):B20-30.

[2] Moon JG, Lee JH. Orthogonal versus parallel plating for distal humeral fractures. Clinics in Shoulder \& Elbow 2015;18(2):105-12.

[3] Sanchez-Sotelo J, Torchia ME, O'Driscoll SW. Complex distal humeral fractures: internal fixation with a principle-based parallel-plate technique. J Bone Joint Surg Am 2007;89(5):961-9.

[4] Garcia JA, Mykula R, Stanley D. Complex fractures of the distal humerus in the elderly. The role of total elbow replacement as primary treatment. J Bone Joint Surg Br 2002;84(6):812-6.

[5] Arnander MW, Reeves A, MacLeod IA, et al. A biomechanical comparison of plate configuration in distal humerus fractures. J Orthop Trauma 2008;22(5):332-6.

[6] Jacobson SR, Glisson RR, Urbaniak JR. Comparison of distal humerus fracture fixation: a biomechanical study. J South Orthop Assoc 1997;6(4):241-9.

[7] Korner J, Diederichs G, Arzdorf M, et al. A biomechanical evaluation of methods of distal humerus fracture fixation using locking compression 
plates versus conventional reconstruction plates. J Orthop Trauma 2004;18(5):286-93.

[8] O'Driscoll SW. Optimizing stability in distal humeral fracture fixation. J Shoulder Elbow Surg 2005;14(1 Suppl S):186S-94.

[9] Self J, Viegas SF, Buford WL, et al. A comparison of double-plate fixation methods for complex distal humerus fractures. J Shoulder Elbow Surg 1995;4(1 Pt 1):10-6.

[10] Ackerman G, Jupiter JB. Non-union of fractures of the distal end of the humerus. J Bone Joint Surg Am 1988; $70(1): 75-83$.
[11] Schuster I, Korner J, Arzdorf M, et al. Mechanical comparison in cadaver specimens of three different 90-degree double-plate osteosyntheses for simulated C2-type distal humerus fractures with varying bone densities. J Orthop Trauma 2008;22(2):113-20.

[12] Jupiter JB, Neff U, Holzach P, et al. Intercondylar fractures of the humerus. An operative approach. J Bone Joint Surg Am 1985;67(2):226-39. 